\title{
Study on Fuzzy Mathematics and Its Applications
}

\author{
Li Yang ${ }^{1}$ \\ ${ }^{1}$ Nanchang Institute of Science \& Technology, Nanchang, 330108 \\ 346591653@163.com
}

KEYWORDS: Fuzzy Mathematics; Application; Advanced Industry

\begin{abstract}
Fuzzy Mathematics produced in 1960s, its formation and development do not want to give up mathematical accuracy, rigor, but to make the objective existence of some of the ambiguity of things and phenomena able to use mathematical methods to study and deal with. The so-called "fuzzy" means things are not clear objective and uncertainty, its roots lie in the difference between the existence of an intermediary transition objective things. For example, say that a man is "tall," which is a vague concept, it is difficult to say how high the count, "tall", because there is no obvious "boundary" between "high" and "low." To solve this problem fundamentally, the US cybernetics expert Professor Zadeh re-examine the foundations of mathematics - set theory, and in 1965 first proposed the concept of fuzzy sets to form a fuzzy mathematics of this new branch of mathematics.
\end{abstract}

\section{Introduction}

As we all know, in the natural sciences, social sciences, engineering and technology in various fields, will involve a large number of fuzzy factors and fuzzy information processing problem, fuzzy technology into almost all areas, the column has a larger international conference on the topic of more than a dozen fuzzy year, various fuzzy technological achievements and products have gradually blurred by the laboratory to society, some have achieved remarkable social and economic benefits such as metallurgy, machinery, petroleum, chemical, electric power, electronics, light industry, energy, transportation, health care, health, agriculture, forestry, geography, hydrology, seismology, meteorology, environmental protection, construction, behavioral science, management science, law, education, military science and so on, each area has its own examples of successful applications such as:

In terms of soft science, fuzzy technology has been used in the investment decision-making, corporate benefit assessment, regional development planning, economic macro-control, in areas such as long-term market forecasting fuzzy. Fuzzy theory will greatly promote scientific and quantitative research soft science. For example, Yamaichi Securities in Tokyo fuzzy logic system to manage large stocks have price assessment certificate, the system uses about one hundred rules to make buy and sell decisions.

In terms of earthquake science, fuzzy technology has been related to the long-term earthquake prediction, seismic hazard analysis and potential source identification, earthquake prediction and earthquake disaster reduction countermeasures and other fields.

In industrial process control, metallurgical furnaces has been achieved fuzzy control, fuzzy control chemical process, cement kiln, glass kiln fuzzy control, etc., fuzzy control technology has become an effective means of control of complex systems, greatly broadened the automatic control Applications. 
In the appliance industry, there have been blurred washing machines, air conditioners fuzzy, fuzzy vacuum cleaners, auto-focus camera and camera blur, fuzzy control televisions, microwave ovens and other household appliances fuzzy, fuzzy logic control these appliances with a very low price varying degrees of change in performance, improve the machine's "IQ", popular in the consumer market.

In the field of artificial intelligence and computer tech, there have been a fuzzy inference engine, fuzzy control computer, fuzzy expert systems, fuzzy database fuzzy speech recognition system, graphics fuzzy character recognition systems, fuzzy robots and other high-tech products, but also the emergence of $\mathrm{F}$-prolog, Fuzz-C and other language system.

In the aerospace and military fields, technology has been used in the aircraft fuzzy butt, C3I command automation systems, etc., such as NASA (NASA) is using fuzzy technology development between the shuttle and the space station as a navigation dock automation system.

\section{Fuzzy Control and Its Application}

Fuzzy mathematics is to solve the problem of blurred branch of mathematics. The so-called "fuzzy" is relative to the "exact" in terms of past problems for researchers mostly "accurate", such a circuit is not turned off, one or the other, never ambiguous reflect the mathematical basis for this phenomenon is a classic set theory: an element of a, either belongs to the set A, either belong to A collection of more than A, it must be one, will not have a third . kinds of situations, but later it was discovered: not all phenomena and concepts such as classical set theory "exact", there are many of the concepts are no clear boundaries - For example, we all like to price stability do not want inflation, then price stability between inflation and whether there is clear boundaries, so the online side is price stability, on the other side is inflation? The answer seems to be negative, people sometimes feel the surroundings, although not inflation, but prices still the swelling quickly. Also, for example, "This car driving too fast, the car was very slow", in the "fast" and "very slow" room, there is no clear boundaries, while intermediate transition. That there are many cars was not "fast" nor "very slow." The so-called fuzzy boundary is not clear and the phenomenon is reflected in the middle of the transition.

From the late 1980s onwards, Japan, the United States, Germany, the United Kingdom have launched a fuzzy control technology research and development, and achieved great success, especially from the 1990s, the rise of Japan fuzzy control technology is a revolution in high-tech fields, Fuzzy control technology has been widely used in washing machines, air conditioners, cameras, vacuum cleaners, electric cookers and other household appliances and industrial, civilian equipment, has attracted the world's attention. In order to ensure competitiveness in the 21st century, Japan fuzzy technology research and development to develop a long-term planning, identified six key development projects: (1) basic research: study the basic concepts of fuzzy mathematical theory and methods to ensure the continuity of application development; (2) the fuzzy computer: Implementing computer processing fuzzy information, including computer The structure, logical memory and storage; (3) machine intelligence: fuzzy information processing, so that the machine can identify and determine the high speed blur information, including intelligent control, robotics, communications, processing and pattern recognition; (4) Display System: achieve human-machine systems, including fuzzy database, fuzzy expert systems and natural language processing techniques; (5) human and social system: the analysis of complex human behavior, including decision support systems, medical diagnostic systems, behavioral and psychological perspective system social and economic model; (6) Natural Systems: Simulation and understand natural phenomena, including the distinction between physical and chemical changes, to determine air pollution, earthquake 
prediction and socio-economic model believe the near future, will be in the practical application of fuzzy control plays an irreplaceable role.

\section{Fuzzy Neural Network Technology}

Our funding from the National Climbing Program Cognitive Science (neural networks) major key projects, try to develop a system to automatically generate the environment at Win-dows fuzzy neural network controller, also known as the fuzzy neural network development system. Research on Fuzzy systems and neural networks relations and fuzzy logic inference neural network (including neural networks fuzzy inputs, uncertain information transmission in the network, the end result of understanding, etc.) will continue research and development trend in the future, especially fuzzy neural network technology with a variety of new technologies and new developments, such as wavelet transform, genetic algorithm combining fuzzy neural network has become the focus of attention of researchers currently neuro-fuzzy technology is mainly reflected in three aspects:

Currently neuro-fuzzy technology is mainly reflected in three aspects: (1) control based on fuzzy neural network; (2) the fuzzy neural network; (3) using fuzzy logic enhanced neural networks.

At present the first practical commercialization of fuzzy neural network technology is the United States Semiconductor Corporation (NSC) of NeuFuz, its main advantage is that it can use fuzzy logic designers than the current general use linear relationship more complex membership function by nerve .NeuFuz network generation nonlinear membership functions describe exponential equations to achieve .Motorola Company believes that these two together can complement each other, look for the commercial value of this technology, so now stepping up the development of these two technologies combine new chip Future research directions neuro-fuzzy technology should focus on the following aspects:

Correspondence between (1) Research on fuzzy logic and neural network neural, fuzzy tuning controller is converted into the equivalent of neural network learning, the use of fuzzy logic to initialize equivalent neural network; (2) expand the fuzzy neural network range of applications, look for fuzzy neural network learning methods are generally fuzzy sets; (3) using fuzzy logic to accelerate the learning speed neural network, and then use this to construct a high-performance neural network fuzzy controller.

\section{Chinese Fuzzy Technology}

Fuzzy set theory in the late 1970s was spread in China. The past 20 years, China's research on the theory and application development has made great achievements, has been listed as one of "international semi-finals." But studies lineup emphasis on theoretical research, while on the application development there is a big gap compared with Japan. Due to various reasons, some of the research results were unable to form applications. In order to rapidly reverse this situation, China has focused on the implementation of "fuzzy technology industry" policy, the development of some obscure product. State Board of Education has invested several hundred thousand dollars at Beijing Normal University, Key Laboratory was established to enhance application development, the National Natural Science Foundation of China in 1989 will be "fuzzy Information Processing and Machine Intelligence" as a major issue research projects, given the strength of hundreds of million of research funding as one of the outcomes of the project, the fuzzy inference engine has been successfully used for inverted pendulum, plastic film and other fuzzy control.

Especially in recent years, the country launched a fuzzy control technology research and development of heat, it is developing very rapidly, and has made gratifying achievements. Several 
large domestic appliance production Group has successfully developed a domestic washing machine fuzzy control, such as the "Little Swan "' Haier "," Duck "," Jin Ling "and other brand smart washing machines, and reached the international advanced level, is generating huge economic benefits. numerous research institutions, universities and also put a lot of manpower and material resources to carry Fuzzy technology research and development, such as Zhengzhou University of Light Industry Fuzzy Control Technology Center, according to market demand, with reference to domestic enterprises Technical indicators developed to launch four special testing equipment, after the trial to good effect. Thermal Engineering, Tsinghua University developed "high frequency air conditioning Fuzzy Control System "on April 9, 1996 by the State Education Commission identified Southwest Jiaotong University is an intelligent control center dedicated to high-tech used in home appliances and industrial research and development institutions. The center completed more than 10 high-tech products development, is generating major economic and social benefits. At present the center is working on technology development projects focused on the State Economic and Trade Commission, "Fuzzy Control Gas Water Heater" and develop "20 000kVA calcium carbide furnace fuzzy control system", will soon be available. In order to adapt to China's fuzzy control technology industry needs major national technology projects SETC established in 1994. "Development and application of fuzzy control technology," in particular includes a child-Fuzzy Control Technology Standardization in October 1994, the national technical supervision. Bureau set up a "National fuzzy control technology standardization working group", convened the inaugural

meeting, adopted the "National Standardization Working Group fuzzy rules", so far two years, we have made significant progress.

\section{Conclusion}

In the future, looking forward to economic forecasting, business sense decision and the timing involved in the field of application of the human machine interface, natural language processing, advertising, market research, medical diagnostics, art, craft and design, but also look forward to the causality forecast difficult to explain natural phenomena, such as air pollution, earthquake prediction, explain climate change, modeling, etc. to make a greater contribution.

\section{REFERENCE:}

[1] Liu Wang. Introduction of fuzzy Chengdu. Sichuan Education Press, 1992.

[2] Xu Yang. fuzzy systems and expert systems to Chengdu. Southwest Jiaotong University Press, 1989.

[3] Wang Shitong, Xiazu Xun Fuzzy Mathematics in artificial intelligence. Mechanical Industry Press, 1991.

[4] Chen Yongyi. Fuzzy Control Technology and Application. Normal University Press, 1993. 